\title{
Economic Disruption, Will It Disrupts Indonesia?
}

\author{
Sheiren Elsafina Hariady \\ (University of Surabaya, 130218085- KP A)
}

Global economy conditions seems not in the best performance that reflects since 2018, which high uncertainty occurs. United States raise their interest rate (The Fed), while Europe and China economics having sluggish growth. In 2020, the global economic must face the economic disruption, in which there must be a new innovative things for business to survive. Indonesia it self, only a big companies that capable to face this disruptions, leaving small companies behind.

Facing the disruption, a company needs to set their focus to Good Corporate Governance (GCG). GCG is very essential for the company, which with GCG management can manage a healthy relationship with the company stakeholders, more effective management system, risk mitigation, etc. Refers to our main journal, there are 3 main dimensions of GCG: conformance, compliance, and performance that expected to build a good company. Implementation of GCG makes companies will have to follow the government standards, to have the full disclosure, transparent, and healthy businesses in order to a sustainable business.

In past few years, starting from 2014 until 2017, the number of business entities increased $21.1 \%$. While the manufacturing industry's investment increased $33.7 \%$ for this last 4 years. Nowadays, a business required to be more easily adapted to rapid environment, such as a new entrance of competitors, the new technology, or even the market demands. The new technology that support digital technology development also impact the labor market, that companies will need workers with technology knowledge and skill. 
In Indonesia, the workforce quality not yet optimize as well as competitive readiness that still need more preparations to before facing the economic disruption. The best strategy for companies to face this phenomenon is by changing the strategy, which is to implement GCG as the explanation before. There is no other way to face the changes except with changes it self, our world nowadays is facing volatility, uncertainty, complexity, and ambiguity (VUCA).

Two companies as examples that implement "the changes" are PT BNI Tbk and PT Hartono Plantation Indonesia (HPI-Agro). BNI did the digital transformation by using their digital products: e-banking, m-banking, QR Codes, etc., while the HPI change their organizational structure: annual to seasonal plants, traditional to modern, and also make a new innovations. Not only by changing the business structure, but business must determined about leadership and management quality. Why? The main reason is with a good management or leadership system, company will be able to face the disruption both from internal or external factors. As the leadership theory says, a good leadership must be result in a good employees too. It means that if businesses have a good leadership system, it will makes their employees feel engage to the businesses. The employee that engage to the company will loyal and contribute or perform better than before. These are only two examples of the implementation of business changes in Indonesia, and as a fact, only few companies dare to take the changes. Mostly, companies will take the changes as a burden or as a thing that should be avoided.

To the details, GCG have so many advantages to the company. With GCG, company will have a robust fundamentals to face this disruption era. The most important things in GCG is GCG can encourage the company performance. A development in performance of course will benefits the company, which its will be able to compete with bigger peers or competitors. In addition, shareholder in finding a good company to invest will consider about how they manage the company, which is reflects from 
GCG as well. Without a good GCG, it is going to be hard to find an investors to support company's financial.

As today, GCG is known as a part of Environmental, Social, and Governance (ESG). From the investor perspective, ESG is very important to decide whether the investors will invest to the company or not will be. Investors called it as ESG investing, where good ESG result surely will attract both foreign and domestic investors due to its diligence and company's sustainability as well. Not only that, GCG can benefits the society around the business too. If we view more detail about GCG, one of the purpose is about social welfare, where GCG pays attention to Corporate Social Responsibility (CSR). In CSR procedure, a business or companies must consider about their environment, such as green environment and how to contribute positively to the society and usually, company will have a special programs to support the society.

To sum up, the disruption is something that all of us have to face, there is no exception. Indonesia as the one of the country that facing this disruption must realize that it can disrupts our business if there is no step taken by the government. But in the fact, Indonesia government has realize this disruptions and starting to implement Good Corporate Governance to mitigate our business from losing the competitiveness in term of over all quality with other countries. The implementation of GCG will impact businesses positively from every side; stakeholder, financial, operational, even the human resource aspect will be affected positively too as well as society around the businesses.

Many people think that disruption that leads of the changes is a bad things, give a bad impact to many businesses, and should avoided. Somehow yes, it can be bad effect for the businesses if they do not know how to take a change, but disruption is also proven that changes is a good things. As we can see today, because of the "changes" there are so many new innovations that open up a new jobs that never existed before. 
So, "disruption" is "relative", it depends on how we interpret the disruption; either a new opportunity or as a thorn. 


\section{BIBLIOGRAPHY}

Tayibnapis, Ahmad Zafrullah and Wuryaningsih, Lucia Endang and Gora, Radita (2019) Companies In Indonesia In The Vortex Of Global Economic Disruption. In: Proceedings of the 16th International Symposium on Management (INSYMA 2019). Advances in Social Science, Education and Humanities Research, 308 . Atlantis Press, pp. 174-177. 